\title{
Learning in Online Continuing Professional Development: An Institutionalist View on the Personal Learning Environment
}

\author{
Mark William Johnson ${ }^{1 *}$, Denise Prescott ${ }^{2}$, Sarah Lyon $^{3}$ \\ ${ }^{1}$ Faculty of Health and Life Sciences, University of Liverpool, UK \{mwj1@liverpool.ac.uk \\ ${ }^{2}$ Faculty of Health and Life Sciences, University of Liverpool, UK \\ \{prescotd@liverpool.ac.uk\} \\ ${ }^{3}$ Faculty of Health and Life Sciences, University of Liverpool, UK \\ \{ssmith86@|iv.ac.uk\} \\ Received on 2 May 2016; revised on 1 September 2016; accepted on 14 October 2016; published on 15 July 2016 \\ DOI: 10.7821/naer.2017.1.189

\begin{abstract}
The nature of institutions is an important question for the Personal Learning Environment (PLE). Whilst the PLE has tended to focus on what is considered to be "non-institutional" technology like social software, most online tools today have a corporate/institutional foundation. How should educators position themselves with learners who have to negotiate different institutional and discursive contexts - whether within corporate social software, formal education, work or the family? Drawing on previous work focusing on how learners maintain personal coherence in organising learning between different contexts, institutional theory is used to revise the model of the learner as a 'viable system', which focuses on the dynamics of transactions that learners make with different institutional entities. Data from an online Continuing Professional Development (CPD) course in acute cancer care is analysed to show how learner transactions indicate constraints bearing upon learners both from their professional context and from their formal educational study. The pattern of learner engagement suggests that the interaction of constraints creates the conditions to motivate in-depth contribution to the course forums. This finding leads us to suggest a rethink of pedagogy within the PLE, and a broader consideration of institutional and other constraints in educational dynamics.
\end{abstract}

KEYWORDS: PERSONAL LEARNING ENVIRONMENT, CONSTRAINT, VIABLE SYSTEM MODEL, TRANSACTION, NEW INSTITUTIONALISM

\section{INTRODUCTION}

Whilst definitions of the Personal Learning Environment (PLE) vary (Fiedler \& Väljataga, 2013; Buchem, Attwell, \& Torres, 2011) its fundamental character as an approach to educational technology which blurs the distinction between processes of learning and processes of self-organisation with technology (Johnson \& Liber, 2008; Wilson et al., 2009; Attwell, 2007) remains an underlying theme. Consequently, champions of the

*To whom correspondence should be addressed:

Faculty of Health and Life Sciences, University of Liverpool,

Brownlow Hill, Liverpool L69 3BX, United Kingdom
PLE advocate learner ownership and control of tools for learning, wherever those tools may be found according to personal preferences. As a critique of institutionally controlled technology like VLEs, PLE advocates raising concerns when institutions mandate the use of their own technologies, or particularly if they proscribe the use of certain technologies beyond the control of the institution. Institutionally centred approaches to technology overlook the way that individuals grow and adapt to various environments through the flexible use of tools as they make their way through the world. In an increasingly technological society, individual flourishing is dependent on technological flexibility. From a theoretical perspective, the concepts of self-efficacy (Bandura, 1997) and 'viability' (Beer, 1972; Johnson \& Liber, 2008) have been used to study the broad mechanisms of individual adaptation and flourishing. Advocates of PLE argue that the capacity to develop self-efficacy, flexibility and adaptability, the essential mechanisms of viability, are compromised if institutions restrict learning technologies to those tools provided and controlled by the institution. However, counter-arguments from institutions cite the need to monitor potentially irresponsible behaviour with social software, protect the university brand and coordinate effective learning by having all learners using the same tools. Additionally, universities have made some of their services available on mobile devices, helping to integrate them better with non-institutional technologies and make the coordination between institutional tooling and non-institutional tooling increasingly seamless (Stubbs, 2011). On balance, despite the PLE advocacy, the status quo regarding institutionally controlled technology has been maintained, and even expanded, with the advent of large-scale VLE platforms in MOOCs.

This paper explores the historical development of the PLE and why its philosophy has failed to have much impact on institutional practice. This has not been for lack of trying: there have been studies of projects which have supported students in the creation of their Personal Learning Environments (Castañeda \& Soto, 2010; Drexler, 2010), and naturalistic studies which have attempted to articulate existing practices with tools (Castañeda \& Adell, 2014). Yet, despite positive words about the PLE, over 10 years after its inception, institutionally centric technology dominates the e-learning landscape. At the heart of the problem, we argue, is a failure in the PLE discourse to 
understand the nature of institutions. In particular, we argue that issues with social media arise partly because of oversight of the institutional nature of social media corporations. We adopt techniques from institutional theory by considering institutions from the perspective of the transactions that their stakeholders have towards them. In supporting the argument, a case study from an online continuing professional development (CPD) module on acute cancer care is analysed from the perspective of the transactions of learners. From this analysis we consider the ways in which learners manage their transactions in different contexts and maintain viability both of themselves and of the institutions with which they engage. In light of this analysis, the complex transactional engagements with non-institutional technology, including social software, can be more closely inspected.

The paper is structured in 4 sections. First, we consider the development of the PLE as an argument of advocacy for shifting the locus of control of educational technology from the educational institution to the learner. Section 2 considers some of the arguments about learner viability, which were put forward by Johnson and Liber using a cybernetic model. These arguments are reframed with the 'coordination of institutional discourses' rather than the coordination of technology at their centre. Section 3 considers data from the acute cancer CPD module, analysing patterns of learner interaction and considering why learners engaged in the way they did. Finally, section 4 offers an explanation in terms of the maintenance of viability of learners, and the coordination of transactions in different institutional domains. The role of formal education in the course is considered as a 'third dimension', which contributes to a discourse dynamic which helps learners to stand outside their work. The conclusion asks the question as to whether a noninstitutional technology could have the same effect.

\section{THEORETICAL BACKGROUND}

The argument to shift the "locus of control" of technology towards the learner was simple: wouldn't it be better for learners to be encouraged to use their own tools for learning particularly when institutional tools would no longer be available to them once they graduate? Wouldn't it be better if different technological services from different sources (for example, communications services from different providers) could be integrated by learners, and the barriers of different interfaces addressed by having standard approaches for managing all kinds of technology? However, these arguments sometimes became overstated in ways that decried institutional technology without a full appreciation of the institutional context in which it exists (Wilson et al., 2009; Attwell, 2007). Some aspects of the PLE advocacy of personal control however, have been vindicated by technical developments. Mobile platforms now feature service integration: messaging tools, calendaring tools and media tools are today provided on most mobile platforms which aggregate similar services under common interfaces. Moreover, the adding of new services has, in the way that was reflected in PLE prototype tools like PLEX (http://www.reload.ac.uk/plex/), become a standardised and easy process - often involving little more than installing an App, or through the use of Widgets. Apps and widgets have simplified the processes of coordinating and increasing the number of services individuals can coordinate. And educational institutions have made their technologies available as Apps that can be more easily coordinated with other social media tools. However, institutions remain tied to their own technologies and barriers remain - particularly once a learner leaves an institution.

Before 2005 and the social software explosion, experiments in peer-to-peer learning technologies (Liber, 2000; Holderness, 2001) provided opportunities for learners to take control of technologies which had no institutional ownership. Liber's "Colloquia" platform featured a peer-to-peer architecture allowing learners to self-organise by creating their own courses, establish private groups and coordinate their own tools either with or without a teacher. With the advent of social media and the exploitation of Service-Oriented architectures (SOA) to drive technological flexibility, the powerful affordances of social technologies gained mass following and approval by many promoters of the PLE. However, social media services were backed by institutions (corporations), in which peer-to-peer technologies, like Colloquia, were not present. This meant that the distinction between a non-institutional technology available to everyone and the technological rigidity of universities became a murkier and almost intractable debate. In particular, advocacy of social software was compromised by the business models of social media corporations, and well as market forces rendering much social software ephemeral.

In the years following the emergence of the PLE and defying some of its predictions, the marketization of education has left institutions more powerful - despite rising fees, student enrolments have risen (McGettigan, 2013). At the same time, social media corporations have quickly become multi-billion dollar enterprises. Learners sit between these competing institutional market forces. What is the relation between a person and the various institutions with which they engage as they move through the world?

The institutional contexts of life involve not only education, but institutions of health, family, public services, welfare, the media and the internet. Each of these makes demands on learners - from simple transactions for the payment of services, to more complex transactions to uphold trust and commitments. Today technologies mediate most of these transactions and most technologies are underpinned by corporations. Therefore a clearer definition of an institution, and particularly a clearer understanding of the institution of technology is required.

\section{INSTITUTIONS AND METHODS}

Institutional theory has a number of representations and a long history. Coase's "theory of the firm" (1937) introduced the study of 'transactions' at the heart of a 'New Institutional Economics', presenting human action as constitutive of social structures. DiMaggio and Powell's general label of “New Institutionalism” (1991) in organisational analysis examined the dynamics of human action in deeper mechanisms of 'institutional isomorphism' as institutions professionalise specific functions like management. Here Coase's transactional focus is given a sociological flavour and more general categories of human interaction are considered as a description of how individuals and institutions relate reflecting broader characterisations of the dynamic relations between structure and agency (Giddens, 1984; Bhaskar, 1979; Archer, 1995). Data analytic, perspectives that view institutional dynamics through the lens of transactions, have become more prominent with increasing capabilities of technology and the capture of much transactional behaviour with technology. 
The word 'transaction' implies some kind of exchange. Whilst in recent years, with the demise of state-funded Higher Education in many countries, the payment for education has become an explicit financial transaction. The most common nonfinancial transaction concerns the completing of assignments in exchange for grades from a tutor, and a certificate at the end of a course (Garrison, 2000). However, exchange itself is poorly understood - even in economics, where assumptions about exchange have been critiqued both within mainstream economics (e.g. von Mises, 1949; Hayek, 1976) and particularly sociology where 'gifts' are considered as forms of exchange (Graeber, 2013; Mauss, 1954; Bataille, 1991). Different types of transaction are evident in educational processes: with personal tools and social media, the learner consciously participates in transactions with friends and others (sometimes in the form of gifts, sometimes in exchange for something), whilst (perhaps less consciously) learners in a transaction with the social media corporations who provide the means of communication and who, in return, target advertising.

In the PLE, the learner engages in many transactions with many different kinds of institution. Technology has transformed this process of transaction management to the point that most transactions are mediated by technology. Whilst many technological barriers to managing transactions have been alleviated, the nature of the management of transactions has not been considered, nor the nature of the transactional relationship with technology itself. The starting point for thinking about the transactional relationship is to consider that learners depend on their engagements with institutions for their survival and development, whilst institutions depend on transactional engagements from individuals in order to maintain their identity: both learners and institutions must remain viable. The modelling of viability of the learner played a role in the articulation of a broader argument about the relationship between the person, institutions and technology in the PLE (Johnson and Liber, 2008), using a model of the 'person as a viable system' based on Stafford Beer's Viable System Model (Beer, 1972). Johnson and Liber argued that Beer's concept of 'viability' is closely related to Bandura's concept of self-efficacy, and that the cybernetic model provided a rich way of examining the necessary components of self-organisation within the complex environment of education.

\section{REVISITING THE LEARNER AS A VIABLE SYSTEM}

The Viable System Model is a cybernetic model of the regulating mechanisms of living systems, whether they are individual organisms or collectives like bee-hives, businesses or universities (Espejo \& Harnden, 1989). Drawing on analogies with the human body, and on the work of cyberneticians such as Ross Ashby whose 'Design for a Brain' (1960) developed an approach to managing complexity (or 'variety'), which postulated the need for multi-level regulatory mechanisms in self-determining living things. Ashby's work articulates a key cybernetic principle: that a complex system can only be managed by another system of equal or greater complexity. This is known as Ashby's Law of Requisite Variety. The VSM brings Ashby's law into a deceptively simple model that Beer used primarily as a discursive tool within business organisations to help optimise organisation. Beer's definition of cybernetics more generally was that it was the "art and science of effective organisation”.
As a recursive model, the VSM is fractal in nature: each viable system comprises viable systems, and each viable system is a component in a larger viable system. Fundamentally, each viable system has to survive in its environment. In accordance with Ashby's Law, for systems to be viable, they must ensure that the balance between their own complexity and the complexity of their environment is equal. This means that the complexity of the environment must either be absorbed by the system, or that the system can amplify its own complexity to match environmental complexities. The process of absorbing complexity is a process of coordinating operations within the environment: most basically, eating, seeking food, avoiding predators; for learners, this list can be amended with getting assignments in, not running out of money, returning library books, socialising, career planning, and so on. Beer calls these operations 'System 1', shown in Figure 1 below as the three circles connected to squares on the bottom left hand side of the diagram (labelled ' 1 '). The coordination requires a metasystem which has oversight of the basic operations, and which can provision resources so that the individual operations work effectively. Within the metasystem, there are 5 specific functions (labelled 2,3, 3*, 4 and 5):

- Operations have to be coordinated in such a way that they do not conflict with each other - in education, the timetable does this. This is called 'System 2';

- Operations have to be adequately resourced and directed in education, ensuring access to adequate information and learning resources is essential. This is called 'System 3' labelled "self-delivery"

- The effectiveness of the coordination needs to be checked getting feedback on performance is essential if learners are to know how they are progressing. This is called 'System $3^{*}$.

- Potential threats in the environment need to be scanned and processes of adaptation or appropriate response coordinated - in education, the changing job market may require new kinds of activities or skills to be learnt. This is 'System 4' labelled "self-development".

- The conflicting balance between the disruption of adaptation and the ongoing requirement for operational management has to be monitored - learners have to establish an identity which gives them sufficient flexibility to adapt to different situations, but which ensures that effective organisation of fundamental operations is maintained. This is System 5, labelled "self-steering”.

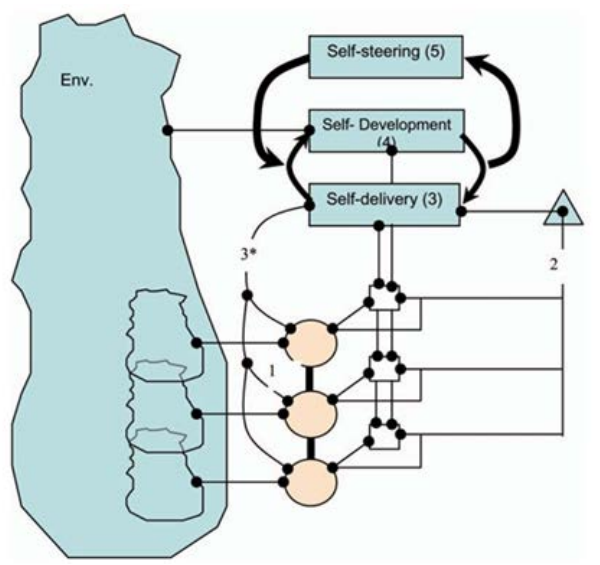

Figure 1. The learner as a Viable System (from Johnson \& Liber, 2008) 


\section{MEASURING SELF-ORGANISATION IN LEARNERS}

A technical way of examining viability and the nature of amplification and attenuation is to see it as autonomous selforganisation within constraints. Constraint is the flipside of variety: the behaviours of viable systems adopt patterns repetitions, common tricks and habits - in response to constraints. Von Foerster points out that the measurement of constraint, or 'redundancy' is an effective index of selforganisation (Von Foerster, 2003, pp. 1-20). Von Foerster uses Shannon's information theory (Shannon \& Weaver, 1949) in arguing that the greater the redundancy, the more predictable the behaviour; the less redundancy, the more erratic and unpredictable the behaviour. In simple educational terms, this description can be used to illustrate some negative aspects of education. For example, 'learning by rote' is a process of applying heavy constraints to produce predictable results. It exhibits lots of redundancy (repetition) and it turns complex human beings into what Von Foerster elsewhere calls 'trivial machines' (Von Foerster, 2003, p140) - 'machines' whose outputs are always predictable if the inputs are known. Like many educationalists, he asks why we would wish to do this, whilst noting that school curricula and examination systems do little else.

Humans are however only rarely subject to a single constraint. Each human being operates within multiple constraints that may be identified individually, but whose net result is not reducible to the action of any single one. We are constrained by bodies, emotions, the emergent effects of childhood attachments, economic conditions, social class, educational opportunity, jobs, family, transport, nutrition, access to healthcare, and so on. Educational processes manipulate the relationship between constraints. Whether it is the confidence to speak a foreign language or to play a musical instrument, what once constrained behaviour to produce erratic behaviour, is overcome (sometimes thanks to a teacher's intervention) and behaviour acquires a broader and more secure range of possibilities. Educational interventions change the interaction of constraints to nurture new patterns of self-organisation.

There has been much work in cybernetics to make the connection between mathematical measurements of complexity and human issues. Recent work on Shannon's information theory by Leydesdorff, has made the connection between discourse dynamics which can be analysed mathematically, and deep phenomenological notions of meaning and expectation, drawing on Husserl's notion of a 'horizon of expectations' and Parson's 'double contingency of communication', where it is argued that communication occurs under conditions of mutual expectation, when each individual entertains expectations of how others are likely to respond to their communication (Leydesdorff, 2006). Leydesdorff's connection between the phenomenology of Husserl and Shannon's concept of information opens up a rich discourse both in sociology (where he considers the successors of Husserl, notably Schutz, Berger and Luckmann and (most importantly) Luhmann), and in mathematical application where he connects to contemporary work in statistical ecology (the work of Odum, and particularly Ulanowicz (2009) who has been working at the frontiers of information theory ecological systems). This work follows a tradition of cybernetic thinking about human issues which stemmed from Bateson's (1980) attempt to articulate an 'ecology of mind'.

Leydesdorff has studied the differences in the dynamics between two communication systems and three (2006). With two, he argues that what emerges is a kind of stasis or 'lock-in' where the lack of an external perspective means that agents are caught in a confusing imbalance between types of communication, for example, between operational priorities and emotional responses. Bateson characterizes this kind of dynamic as a 'double-bind': a confusion about the levels at which communications are understood, where messages at one level are contradicted by messages at another, alongside a prohibition in speaking about the dynamics of the situation (for example, where a parent says "I love you" to a child, but their body language is unwelcoming). Bateson argues that in order to deal with a double-bind, it is necessary to stand outside it and view it objectively. In a classic paper on Alcoholics Anonymous (Bateson, 1980), he argued that this meant 'submitting to a higher authority' - in other words, bringing in a third dimension. Reflecting this involvement of a third dimension, Leydesdorff has similarly argued that complex generative dynamics require at least three domains of interaction. From these abstract approaches, we can turn to a concrete example of learners having to coordinate their behaviour across different environments. In an educational course - particularly one that is focused on learners in a professional context - there is an opportunity to map the different discursive domains that learners engage with (for example, professional practice, personal concerns and formal educational practice) on to a classification of the online transactions that learners make as part of their learning. The variation in transactions is reflected in different kinds of speech act that learners make in different circumstances. We can speculate on the relationship between the variety of speech acts in online transactions and the maintenance of individual viability for learners on the course. Fundamentally, it is possible to consider ways in which the constraints learners operate within are made apparent through discourse, and then to consider how learners find ways of reorganising themselves within their constraints.

\section{THE CPD COURSE DATA SAMPLE}

The CPD course in Acute Oncology at the University of Liverpool attracts mature post-graduate students internationally who work at various levels in the health-care system, usually with some relation to cancer diagnosis or treatment. Students have online contact with experts in the clinical management of cancer, as well as having the opportunity to connect with other practitioners dealing with similar issues. The course is creditbearing (although students can opt-out of assessment if they wish), and students are assessed through the production of 2 pieces of written work. As a formal institutional course, students are presented with the VLE (Blackboard) as their platform for engagement. There is no explicit connection to personalised technology, although this is personalised learning in the sense that learners in diverse professional settings articulate their own inquiries and experiences - similar to the interpretation of Powell, Millwood and Tindal (2008). The provided technology is a medium through which learners can interact with other online participants in response to the particular topics presented to them. The data provides an opportunity for inspecting the institution's role as the hub for 
online transactions between learners and the way this may shape the conditions for learners to feel safe when engaging in authentic discussions with one another.

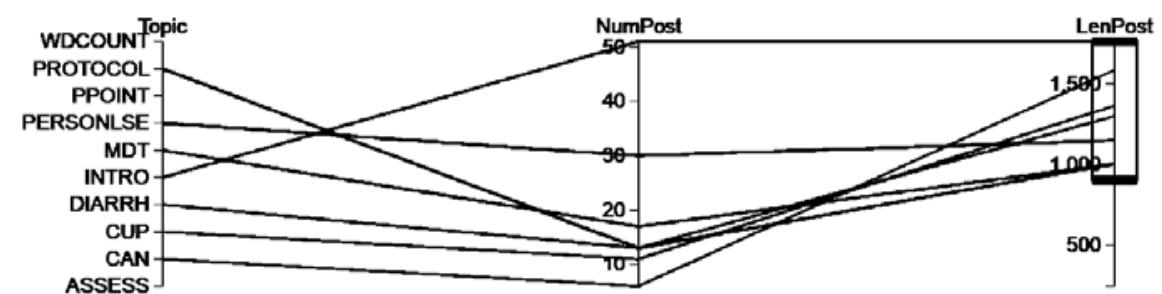

Figure 2. Post lengths for course topics

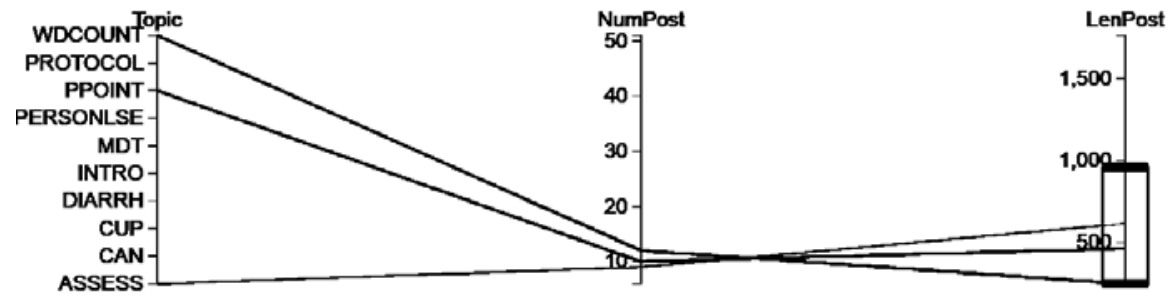

Figure 3. Post lengths for course administration queries

The dataset for the analysis comprises one instance of the course, with a total of 188 posts made by 26 students and 3 instructors. Online CPD courses differ from traditional learning in that technology is used to coordinate discussion and activity that connects multiple domains of practice. The emphasis is on self-coordination between work, personal and educational environments. Learners must negotiate their interactions and honour commitments across these different domains: personal viability and self-efficacy necessitates the making of a variety of different kinds of transaction. Our aim here is a deeper understanding of how transactions are managed by learners. More deeply, we seek to illuminate the ways transactions with social software corporations are managed when learners engage with technologies outside formal education. The personal coordination of technology becomes an issue of the personal coordination of transactions with multiple institutions, of which the institution behind the technology is one.

Over $50 \%$ of the posts in the dataset are between 300-600 words in length. Most are thoughtful and reflective. Given that not all online CPD courses engage learners to this extent, there is a question as to why learners have committed so much effort in writing lengthy posts in this course. Moreover, there is a question as to the extent to which learners engage in conversation with one another: many of the posts are testimonies of incidents at work. Beyond 'agreeing' with different testimonies, learners do not appear to ask each other questions or engage in detailed conversation. Given that conversation has formed such an important part of online pedagogical theory (e.g. Laurillard's (2001) conversation model), there is a question as to whether this presents a challenge to accepted pedagogical theory, and how it might be explained either within conversational pedagogy, or in a different way.

Quantitative data concerning the key features of learner interaction are gathered and presented using a Parallel Coordinates visualisation (Inselberg, 2005). This data includes the number of posts, their length and quality as well as analysis of the distribution of specific kinds of speech act, including questioning, expressing opinion and feeling, and the declaration of imperatives relating to either professional practice or study.

\section{RESULTS}

Figures 2 and 3 show a categorisation of posting topics, the number of posts within each topic, and the average word count expressed using parallel coordinates. The post length may be taken as an indicator of how much effort each transaction costs the learner. There is a clear divide between transactions that occur under topics that relate to the specifics of cancer care, and those relating to issues specific to the course. The latter category attracts functional posts like "how many words does the assignment have to be", whereas the former lengthy bodies of text are usually between 400-600 words in length which must have taken learners some time to compose.

In analyzing the distribution of particular kinds of speech act over the course, a simple query is to examine the number of questions that are asked by learners of each other or of tutors shown in Figure 4. Here, we see a concentration of questions within posts about administrative matters of the course directed at the tutors. Questions which are asked regarding the specific topics of the course (for example, protocols for treatment or multi-disciplinary teams) are often either rhetorical, or are social requests between learners (for example, "why don't you come and visit us?”). Few queries concern the details of each other's experiences in practice or each other's understanding. However, the number of practical queries about 'passing the course' indicates that passing really matters to the students. The course rules act as a constraint on learner behaviour.

Longer posts occur within specific topic headings of cancer care: the use of multi-disciplinary teams for diagnosis (cancer is a complex condition and common practice has been to involve many different specialisms in addressing care issues), the issue of cancers where the primary cancer is unknown (Cancer with Unknown Primary - or “CUP” diagnosis), issues concerning the admission and triage of patients, problems with side-effects of medication - particularly diarrhoea, and issues of personalization in cancer care. Within these topics, learners articulate the operating conditions in their different situations, often recognizing the descriptions of others ("I agree with what's been said”, "others have pointed to the difficulties in...”). The length of the posts is, at the very least, indicative that each 
learner feels they have a lot to say. It is also indicative that in describing their situations, there is an expectation that others in the forum will understand. The issue of having a lot to say, and the expectation that others will understand are connected. As both Husserl's concept of 'horizons of expectations' and Parson's 'double-contingency of communication' predict, feeling that one's utterances will be understood is an important condition to be being able to make utterances in the first place. The extent to which learners express personal opinions in different areas, whilst articulating the imperatives (the things that have to be done) of the situation they work in is shown in figure 5.

Leydesdorff has suggested that shared expectations can be measured statistically. Most basically, the prevalence of key words is indicative of constraint conditions that make it more likely for such words to be used. The most frequently used word across the whole dataset is the word "patient" (used 431 times across 188 posts) and the word "team" (used 106 times). Continual use of the word 'patient' is a sign of one of the principal constraints in the whole system (as one would expect!). With patients come obligations, and so imperative words like "must/essential/have to/ensure" as well as references to "team/staff" all indicate the associated professional constraints within which individuals have to work. The conflicting demands of the work environment are revealed in comments such as "[with] lack of resources within units [...] given such restraints, it is not always possible to give "best care" despite staff striving to do so.”. A deeper analysis of these institutional constraints might examine the policy documents and working practices within each setting - although this analysis is beyond the scope of the current paper.
The long posts which detail the complexities of the working environment, alongside expressions of how individuals feel in these environments stand in contrast to the operational (but no less meaningful) concerns of students in wanting to pass the course. This contrast is highlighted in figure 6. Here the data diverges according the length of posts, and particularly for the expression of opinion. Whilst it is obvious that learners are unlikely to express opinions in asking about the word counts of assignments, the graph does highlight the fundamental differences between the different kinds of transaction, which are managed by learners and the extent that this difference co-exists.

Does this mean that different transaction types are codependent? Are the short administrative transactions about the course a necessary accompaniment to longer and thoughtful posts about professional practice? An explanation as to why learners write so much and in so much detail about their professional experiences cannot ignore the evidence that learners are keen to submit to the assessment regime of the course. In more formal terms, there are two 'codes of expectation' here: there is one for communications about the course, and another for reflections on work. Learners appear comfortable to talk about the course rules and about their professional experiences, knowing that these are common constraints bearing upon everyone. Confirmation of each other's professional experiences is a particularly important part of this. The recognition of common constraints not only sends a fundamental signal that "you are not alone", but also creates the conditions where the complex dynamics that operate within the work environment can

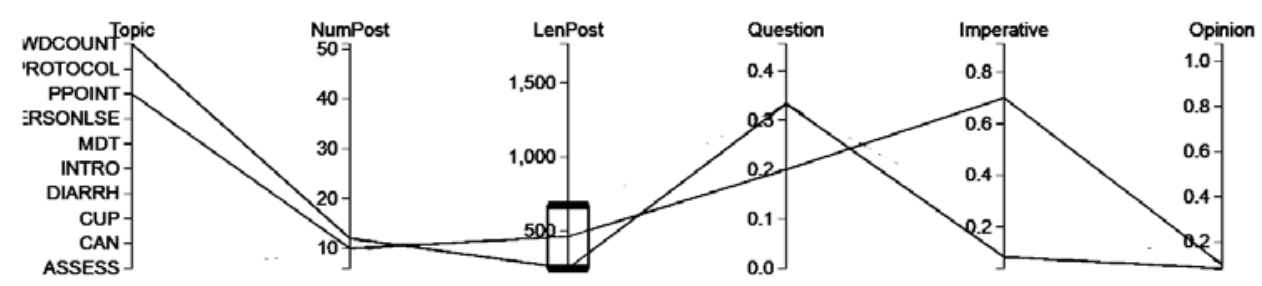

Figure 4. Questions asked for administrative topics

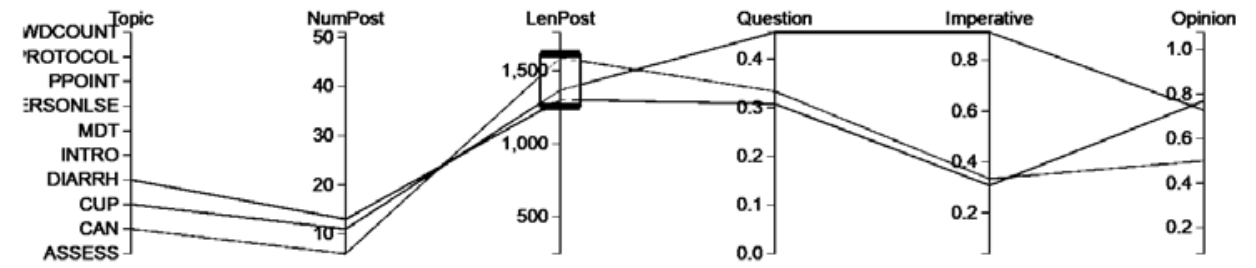

Figure 5. Expression of opinion, and questioning and imperative statements in course topics (Diarrhoea (DIARRH), Cancer of Unknown Primary (CUP), Cancer admissions (CAN)

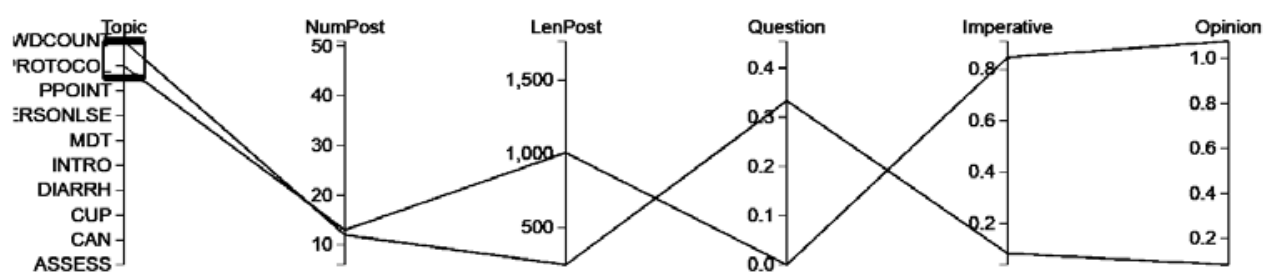

Figure 6. contrast between expression of opinion and imperative statements between course admin transactions and course content (protocols for cancer care) 
be objectified: learners can stand outside their work situation and observe its dynamics. The constraints of the formal course add to the mix of constraints that learners are already subject to. In this way, the course provides what Leydesdorff would recognise as a "third dynamic". Students appear willing to submit to the higher authority of formal education and as a result are 'freed' to share their experiences.

\section{DISCUSSION}

The PLE conceived as an intervention in the technological environment to help learners maintain their viability across the many different environments of life placed focus on the internal regulating mechanisms of the 'viable learner' and tended to ignore the specific impact of the environment itself. The study of CPD suggests that the constraints of the environment have a greater bearing on the management of learner viability than previously considered. Moreover, environmental constraints are distinguished as belonging to different institutions - work, education, home - and that each of these different institutional contexts carries with it distinct sets of expectations and discourses. Institutional theory suggests that the viability of different institutions depends on the discursive transactional behaviour of members of those institutions: institutions are constituted by discourses, which are maintained by those engaging with institutions. Transformation of institutions depends on transformation of agents (learners), and vice-versa. This in turn depends on the complex interactions between different institutional discourses. Whilst the cancer course presents no evidence of institutional transformation, and indeed not that much direct evidence of learner transformation, it clearly displays processes whereby learners identify the shared dynamic they are caught in. The rules of the educational institution operate as a third constraint facilitating articulation of other constraints. Nevertheless there remains a question, pertinent to the PLE, as to whether the institution with its rules, barriers, and declarations of educational scarcity, is a necessary component: could the same outcome be possible without institutional technology, or indeed without the educational institution?

Educational technology in the CPD course facilitates communication by applying constraint, both through the technology itself and in the rules of participation and assessment. The difference between informal learning and formal learning is a difference in the constraints that bear upon learners. Whilst messaging services like Twitter apply simple constraints on users (messages have to be no more than 120 characters), or email lists and forums can be managed according to topics, within the breadth of possibilities for online communication outside an institution, almost anything is possible. The result is that it can be harder to establish a common set of expectations in online communication, and without this, it is difficult to establish sufficient trust between participants to ensure that communications are not misunderstood or have negative consequences. Issues of trust are further complicated by the fact that transactions with social media services can serve multiple purposes: on the one hand, they are transactions in the management of communication with others; on the other, they are part of a bargain with the providers of services which contribute to the business models that help providers make profits. Business interests of service providers can coincide with some aspects of motivation for communication by individuals. Particular communications can exploit mechanisms of amplification and promotion within the social media domain (for example, by going 'viral'), bringing attention both to the service provider and to the participant in communication. Unpleasant examples of this include 'trolling', 'flaming' or other thoughtless communicative acts that can land their perpetrators in trouble. The latent constraints of social media business models appear to encourage this, even if they overtly condemn it because it brings traffic and advertising opportunities. Fundamentally, the latent institutional nature of social software can be a barrier to personal learning.

Beyond the technology, this study highlights issues connected to conversation in pedagogical theory. Whilst learners come to an appreciation of the work situation they are in by reading and recognising other's experiences, there is nothing in Pask's conversation theory to explain how motivation for articulating experiences arises. In our study, we have suggested that the principal ingredient for motivation to articulate experiences of work is the constraint of the formal course and its assessment mechanisms. The causal effects of this are complex and their articulation is beyond the scope of this paper.

\section{CONCLUSIONS}

The question about the ways learners use technology to maintain viability across different walks of life is a question as to how learners position themselves within the dynamics of multiple discourses, and how educators might seek to position themselves as an additional constraint within those dynamics. Viable learners and viable institutions are co-determining: technological coordination in the PLE entails institutional coordination whether it is the institution of education in the form of universities or work, or it is the institution of technology in the form of social software corporations. We have upheld the view of New Institutionalism that institutions are maintained through the transactions that individuals have with them.

Different discourses produce different constraints. There are ways that different constraints interact to create the conditions for learners to observe and reflect on the discourse dynamics they are caught in. On the CPD cancer module, the constraints of formal education contributed to a dynamic that fostered shared expectations between participants, which led to the articulation of the dynamics of the workplace and personal reactions to it. We have argued that to achieve this with social software would be much more difficult because the kinds of constraints applied by the technology are fundamentally different, and with different constraints, the conditions of trust and shared expectation cannot be established. In particular, the latent institutional form of social software creates conflicting pressures to acquiesce with hidden agendas of social media companies.

Understanding the personal viability of learners in the context of negotiating transactions with different institutions provides a new perspective on the PLE. On the one hand, this sheds light on those factors in institutional CPD courses, which can lead to rich learner engagement. On the other hand, it highlights deeper mechanisms of self-organisation, which might be realisable in the context of technologically mediated communication. Fundamentally, deep discussion, inquiry and learning about the complex environments each of us coordinates depends not on tools, but on interpersonal trust and shared expectations. We have shown how shared expectations can emerge in a complex dynamic between different constraints, where one of them is formal education. In our case, formal education provides a clear example of a constraint that creates space for learners. However, 
to understand its dynamics is to understand that such constraints need not only be produced in this way. The conditions for friendship, peer mentoring, collaborative inquiry and social movements are clearly not bounded by formal education. It remains a hope of the PLE that we should, as Margaret Mead is reputed to have remarked: "Never doubt that a small group of thoughtful, committed citizens can change the world; indeed, it's the only thing that ever has" (quoted in Sommers and Dineen, 1984, p. 158).

\section{REFERENCES}

Archer, M. (1995). Realist Social Theory: the Morphegenetic Approach. Cambridge: Cambridge University Press. doi: 10.1017/CBO9780511557675

Ashby, R. (1960). Design for a Brain: The Origin of Adaptive Behaviour. New York: John Wiley. doi:10.1037/11592-000

Attwell, G. (2007). The Personal Learning Environment - the future of E-learning? E-Learning Papers, 2(1), 1-8. Retrieved from http://digtechitalia.pbworks.com/w/file/fetch/88358195/Atwell\%202007.pdf

Bandura, A. (1997). Self-efficacy: The exercise of control. New York: WH Freeman.

Bataille, G. (1988). The Accursed Share: An essay of General Economy Zone Books. New York: Zone Books.

Bataille, G. (1991). The Accursed Share: Volume 1. New York: Zone Books.

Bateson, G. (1980). The Cybernetics of "Self": A theory of alcoholism. In G. Bateson (Ed.), Steps to an Ecology of Mind (pp. 309-337). New York: Ballantine.

Beer, S. (1972). Brain of the Firm. Chichester: Wiley.

Bhaskar, R (1979). The Possibility of Naturalism: A philosophical critique of the contemporary human sciences Atlantic Highlands. N.J: Humanities Press.

Buchem, I., Atwell, G., \& Torres, R. (2011). Understanding Personal Learning Environments: Literature review and synthesis through the Activity Theory lens. In Proceedings of the the PLE Conference 2011, Southampton, UK. Retrieved from http://journal.webscience.org/658/

Castañeda, L., \& Soto, J. (2010). Building personal learning environments by using and mixing ICT tools in a professional way. Digital Education Review, 18, 925.

Coase, R. H. (1937). The Nature of the Firm. Economica, 4(16), 386-405. doi:10.1111/j.1468-0335.1937.tb00002.x

DiMaggio, P., \& Powell, W. (Eds.), (1991). The New Institutionalism in Organisational Analysis. Chicago: University of Chicago Press.

Drexler, W. (2010). The networked student model for construction of personal learning environments: Balancing teacher control and student autonomy. Australasian Journal of Educational Technology \& Society, 26(3), 369-385. doi:10.14742/ajet.1081

Espejo, R., Harnden, R. (1989). The Viable System Model: Interpretations and Applications of Stafford Beer's VSM. Chichester: Wiley.

Fiedler, S., \& Väljataga, T. (2013). Personal learning environments: a conceptual landscape revisited. E-Learning papers, 35, 1-16. doi:10.4018/978-1-46662467-2.ch014

Giddens, A. (1984). The Constitution of Society. Oakland: University of California Press.

Graeber, D. (2013). Debt: The First 5,000 Years Brooklyn. NY: Melville House Publishing.

Hayek, F. (1976). Law, legislation and Liberty (Vol. 2). London: Routledge/Kegan Paul.

Holderness (2001, October, 6th). University Challenge. New Scientist.

Inselberg, A. (2009). Parallel Coordinates: VISUAL Multidimensional Geometry and its Applications. New York: Springer. doi:10.1007/978-0-387-68628-8

Johnson, M., \& Liber, O. (2008). The personal learning environment and the human condition: from theory to Teaching Practice. Interactive Learning Environments, 16(1), 3-15. doi:10.1080/10494820701772652

Laurillard, D. (2001). Rethinking University Teaching: A Conversational Framework for the Effective Use of Learning Technologies. London: Routledge.

Leydesdorff, L. (2006). The Knowledge-based economy: Modelled, Measured, Simulated. Boca Raton, Florida: Universal Publishers.

Liber, O. (2000) Colloquia - a conversation manager Campus Wide Information Systems, 17(2), 56-62. doi:10.1108/10650740010326618

Powell, S., Millwood, R., \& Tindal, I. (2008). Personalized Learning and the Ultraversity Experience Interactive Learning Environments, 16(1), 63-81. doi:10.1080/10494820701772710

Mauss, M. (1954). The Gift. London: Cohen \& West.
McGettigan, A. (2013). The Great University Gamble: Money, Markets and the future of Higher Education. London: Pluto Press.

Sommers, F. G., \& Dineen, T. (1984). Curing Nuclear Madness. Toronto: Methuen.

Shannon, C., \& Weaver, W. (Eds.) (1949). A Mathematical Theory of Communication. Urbana: University of Illionis Press.

Stubbs, M. (2011). Service-oriented architecture and curriculum transformation at Manchester Metropolitan University. Campus Wide Information Systems, 28(4), 299-304. doi:10.1108/10650741111162770

Ulanowicz, R. (2009). A Third Window: Life Beyond Newton and Darwin. West Conshohocken: Templeton Press.

Von Mises, L. (1949). Human Action: A Treatise on Economics. New Haven: Yale University Press.

Von Foerster, H. (2003). Understanding Understanding. New York: Springer. doi:10.1007/b97451

Wilson, S., Liber, O., Johnson, M., Beauvoir, P., Sharples, P., \& Milligan, C. (2007). Personal Learning Environments: Challenging the dominant design of educational systems. Journal of E-learning and Knowledge Society, 3(2), 2738.

\section{How to cite this article:}

Johnson, M. W.; Prescott, D.; Lyon, S. (2017). Learning in Online

Continuing Professional Development: An Institutionalist View on the Personal Learning Environment. Journal of New Approaches in Educational Research, 6(1), 20-27. doi: 10.7821/naer.2017.1.189 